\title{
"A música instrumental de Beethoven"
}

\section{E. T. A. HoFfmann}

Quando falamos da música como arte autônoma, não deveríamos ter em mente apenas a música instrumental? Pois essa, ao rechaçar todo auxílio e mistura com outra arte (a da poesia), expressa com pureza a essência que lhe é peculiar e que se reconhece unicamente nela. Ela é a mais romântica de todas as artes, quase poderíamos dizer a única verdadeiramente romântica, pois se ocupa apenas do infinito. ${ }^{1}$ A lira de Orfeu abriu os portões dos Infernos. A música franqueia ao homem um reino desconhecido - um mundo que não possui nada em comum com o mundo exterior sensorial ao seu redor -, um reino onde ele abandona todo sentimento determinado para entregar-se a um anseio [Sehnsucht] indizível.

Chegaram vocês sequer a pressentir tal essência peculiar, ó pobres compositores instrumentais que se empenham com tanto afinco em representar determinadas sensações ou até mesmo acontecimentos? Como é que pôde ocorrer-lhes tratar plasticamente a arte que é diametralmente oposta à plasticidade? O fato é que suas auroras, suas tempestades, suas Batailles des trois Empereurs ${ }^{2}$ etc. decerto se provaram equívocos bastante risíveis e foram merecidamente punidas com o completo esquecimento.

No canto, em que a poesia sugere determinados estados de espírito por meio de palavras, a força mágica da música atua como o maravilhoso elixir dos sábios, do qual bastam parcas gotas para tornar toda bebida mais saborosa e magnífica. Toda paixão - amor, ódio, ira, desesperança etc. - tal como nos é dada pela ópera, a música a reveste com o esplendor purpúreo do romantismo, e mesmo aquilo que é criado a partir da vida nos guia para fora da vida, para o domínio do infinito.

${ }^{1} \mathrm{O}$ cotejo com a redação original da resenha, publicada no Allgemeine Musikalische Zeitung de 1810, revela duas modificações introduzidas nesta frase: uma mudança no advérbio, de "puramente romântica" (grifo do original) para "verdadeiramente romântica"; o acréscimo, na versão da Kreisleriana, da subordinada causal. As demais diferenças estilísticas entre as duas redações - não todas, mas apenas algumas que julgamos mais significativas - serão doravante indicadas em nota com a sigla AMZ.

${ }^{2}$ Há basicamente duas obras às quais Hoffmann poderia estar remetendo: à peça sinfônica $L a$ grande bataille d'Austerlitz, surnommée la bataille des trois empereurs - Fait historique arrangé à grande orchestre, de Louis-Emmannuel Jadin (1806) ou à obra praticamente homônima de Jacques-Marie Beauvarlet-Charpentier, do mesmo ano (apud David Charlton, que também reporta o arranjo para piano solo da primeira). Tais obras pretendiam representar, por meio de recursos musicais, os eventos da célebre Batalha de Austerlitz, dita dos Três Imperadores. Quanto a outras obras aqui unicamente sugeridas - "auroras", "tempestades" -, é de se notar que a primeira redação da resenha da Quinta Sinfonia (AMZ, ver apresentação e nota anterior) trazia em seu lugar outra menção de caráter explícito, nomeadamente às "sinfonias deste tipo de Dittersdorf", a qual foi suprimida na presente redação da Kreisleriana. 
Tal é a força do feitiço da música; à medida que se torna cada vez mais potente, ela tem de romper todo vínculo com outra arte.

É evidente que o fato de compositores geniais terem alçado a música instrumental ao patamar de hoje não se deve apenas à melhoria dos meios de expressão (aperfeiçoamento dos instrumentos, maior virtuosidade dos intérpretes), mas a uma apreensão mais íntima e profunda da essência peculiar da música.

Mozart e Haydn, os criadores da atual ${ }^{3}$ música instrumental, foram os primeiros a revelar-nos a arte em toda a sua glória; mas quem a examinou com total dedicação e soube penetrar-lhe a essência mais íntima foi... Beethoven! As composições instrumentais desses três mestres estão imbuídas de um mesmo espírito romântico, que advém de uma mesma apreensão interior da essência peculiar da música; no entanto, o caráter de suas composições se diferencia notavelmente.

Nas composições de Haydn, reina a expressão de um ânimo [Gemüt] infantil e terno. Suas sinfonias nos conduzem a bosques verdejantes a perder de vista, a uma divertida e colorida algazarra de pessoas alegres. Rapazes e moças flutuam em danças de roda; crianças risonhas, espiando por detrás de árvores e de roseiras, lançam provocativamente flores umas nas outras. Uma vida cheia de amor e beatitude como antes do pecado, eternamente jovem; nenhum sofrimento, nenhuma dor, apenas um doce e melancólico almejar [Verlangen] pela figura amada, que flutua a distância, em meio ao albor do crepúsculo, sem se aproximar nem desaparecer, e cuja presença impede a chegada da noite, pois é ela mesma o crepúsculo que ilumina o monte e o bosque.

Mozart nos conduz às profundezas do reino dos espíritos. Somos tomados de medo, mas sendo esse livre de martírio, é mais um indício [Ahnung] do infinito.

Amor e melancolia ressoam em afáveis vozes de espíritos; surge a noite ${ }^{4}$ num esplendor púrpura claro e, em meio a um anseio indefinível, seguimos as figuras que, acenando para nós amigavelmente de suas fileiras, revoam através das nuvens em perenes danças de esferas. (A sinfonia em Mi bemol de Mozart, conhecida como "Canto de cisnes". ${ }^{5}$ )

Também a música instrumental de Beethoven nos desvela um domínio, o do monstruoso e do incomensurável. Raios luminosos dardejam pela noite escura desse reino, e percebemos sombras gigantescas oscilando para cima e para baixo, cercando-nos cada vez mais de perto e aniquilando a nós, mas não à dor do anseio infinito. Nele, cai e sucumbe toda felicidade que se elevara rapidamente em tons jubilosos, e é apenas nessa dor de amor, esperança, alegria, que consome a si mesma sem no entanto exterminar-se, que nosso peito quer explodir num estrondo

${ }^{3}$ AMZ: da nova.

${ }^{4}$ Há aqui uma divergência dentre diferentes edições estabelecidas: algumas, como a resenha original do AMZ, trazem "Macht" ("poder"); outras, como a edição histórico-crítica da Kreisleriana a cargo de Carl Georg von Maassen, que serviu de base para a presente tradução, "Nacht" ("noite") (cf. E. T. A. Hoffmanns sämtliche Werke, Maassen [ed.], Munique e Leipzig, Müller, 1908, v. 1).

${ }^{5}$ A sinfonia $n^{\circ} 39$, K. 543, obra tardia de Mozart. A alcunha caiu em desuso, ou não foi tão disseminada quanto Hoffmann nos faz crer. 
reunido de todas as paixões a plena voz, e que seguimos vivendo e nos tornamos extasiados visionários! ${ }^{6}$

O gosto romântico é raro, e mais raro ainda o talento romântico; por isso, só muito poucos são capazes de tanger a lira cujo ressoar franqueia o maravilhoso reino do romântico.

Haydn apreende romanticamente o humano na vida humana; ele é mais comensurável, mais apreensível para um maior número de pessoas.

Mozart toma mais em consideração o sobre-humano, o maravilhoso que habita o espírito interior.

A música de Beethoven impulsiona a alavanca do medo, do pavor, do estupor, da dor, e desperta precisamente aquele anseio infinito que é a essência do romantismo. Ele é, portanto, um compositor romântico puro. ${ }^{7}$ Não seria por isso que é menos bem-sucedida sua música vocal, a qual não proporciona o caráter do ansiar indeterminado, mas só representa afeições determinadas, tais como percebidas no domínio do infinito, por meio de palavras? ${ }^{8}$

O poderoso gênio de Beethoven rechaça o gosto musical vulgar; tenta em vão rebelar-se contra ele. Mas os sábios juízes, olhando ao redor com expressão altiva, garantem: dão-nos sua palavra, pode-se acreditar neles - pois são homens de grande discernimento e visão profunda -, o bom B. não careceria absolutamente de uma fantasia muito rica e vivaz, mas ele não saberia domá-la! Nem se poderia falar em seleção e conformação de ideias, mas, utilizando-se do assim chamado método genial, ele descarregaria tudo num arroubo, da maneira como a fantasia, trabalhando no calor do momento, lhe sugeriria naquele instante. Mas e se for apenas a fraca perspicácia de vocês a evadir a profunda coesão interna de cada composição de Beethoven? Se somente a vocês se deve o fato de não entenderem a língua do mestre, compreensível para os iniciados, e de as portas do sacrossanto permanecerem fechadas para vocês? Em verdade, o mestre, que em termos de lucidez [Besonnenheit] é comparável a Haydn e Mozart, separa o seu eu do reino interior dos tons e impera sobre ele como senhor absoluto. Geômetras estéticos queixaram-se com frequência da completa falta de unidade e coesão interna em Shakespeare, onde um olhar mais penetrante vê vicejar uma bela árvore, e folhas, flores e frutos crescem a partir de um gérmen; assim também apenas uma incursão muito profunda na música instrumental de Beethoven é capaz de revelar a elevada lucidez que é inseparável do verdadeiro gênio e é fomentada pelo estudo da arte..$^{9}$ A obra instrumental de Beethoven que comprova tudo isso no mais alto

${ }^{6}$ Geisterseher: literalmente, "videntes de espectos". A referência ao mundo dos espíritos e sua percepção é frequente e fundamental ao longo de todo o texto.

${ }^{7} A M Z$ traz como acréscimo o parêntese: "(e por isso mesmo um [compositor] verdadeiramente musical)".

${ }^{8}$ AMZ complementa: "e sua música instrumental raramente fala às massas". Todo o trecho a seguir foi reescrito para a versão da Kreisleriana. Embora o teor tenha se mantido em boa medida o mesmo, as variantes são em número grande demais para serem indicadas aqui.

${ }^{9}$ Hoffmann responde, aqui, a um tipo de crítica contemporânea mais comum em relação a peças da segunda fase da carreira de Beethoven, em que ele já começava a se distanciar do modelo 
grau é a extremamente magnífica e engenhosa Sinfonia em Dó menor. Como essa maravilhosa composição conduz o ouvinte de modo irresistível a um progressivo clímax, adiante, ao domínio espiritual do infinito! Nada poderia ser mais simples do que o motivo principal do primeiro Allegro, constituído apenas de dois compassos e que, começando em uníssono, não permite ao ouvinte sequer identificar a tonalidade. ${ }^{10} \mathrm{O}$ tema secundário [Nebenthema] só acentua ainda mais caráter do pavoroso e irrequieto anseio que essa frase encerra! O peito, pressionado e assustado pelo presságio de algo monstruoso, pela ameaça de destruição, parece arfar perceptivelmente, buscando violentamente aliviar-se, mas logo uma figura amiga se aproxima, radiante, e ilumina a noite profunda e assustadora. ( $\mathrm{O}$ amável tema em Sol maior, tangido inicialmente pelas trompas em Mi bemol maior.)

Como é simples - diga-se novamente - o tema sobre o qual o mestre erigiu o conjunto, mas quão maravilhosamente ele soube encadear todos os temas secundários e motivos episódicos [Neben- und Zwischensätzte] por meio de sua correlação rítmica, de modo que só contribuem para desenvolver progressivamente o caráter do Allegro, que havia sido unicamente aludido por aquele tema principal. Todas as frases são curtas, quase sempre consistindo em dois, três compassos, e ainda por cima subdivididas pela constante alternância entre os sopros e as cordas. Seria de acreditar que tais elementos só pudessem dar origem a algo desconjuntado, inapreensível; ao contrário, é justamente esse encaminhamento do todo, assim como a seguida repetição, uma após a outra, de motivos e de acordes isolados que intensifica a sensação de um anseio inominável até o mais alto grau. Sem nem falar no tratamento contrapontístico, que testemunha um profundo estudo da arte. Analogamente, são os episódios [Zwischensätze] e as frequentes variações do tema principal a evidenciar como o mestre foi capaz de apreender em seu espírito o conjunto e todos os seus traços característicos, e perfazê-los pela reflexão.

clássico então canonizado. Um exemplo notável de alegada falta de unidade encontra-se na notícia (de autoria anônima, como de costume) referente a uma soirée em Viena em que se executara a Terceira Sinfonia: "Essa composição longa, de execução extremamente difícil, é na realidade uma fantasia levada longe demais, audaz e indomada. Não lhe faltam passagens surpreendentes e belas, nas quais é preciso reconhecer o espírito enérgico e talentoso de seu criador: muito amiúde, porém, ela parece perder-se completamente na ausência de regras [...]. O Ref. decerto pertence aos mais francos admiradores do Sr. v. Beethoven; mas quanto a esta obra deve no entanto observar que contém elementos rascantes e bizarros além da conta, o que dificulta sobremaneira a visão do todo e compromete a unidade quase a perder-se" (AMZ, ano de 1805, n. 20 [13 de fevereiro], col. 321). O mesmo artigo, diga-se, enaltece em contraste a Primeira Sinfonia do compositor. Ao longo da primeira década do século XIX, a recepção da obra beethoveniana se tornará em geral menos polêmica (cf. Wallace, Beethoven's critics, Cambridge, Cambridge University Press, 1988).

${ }^{10} A M Z$ descreve a (temporária) indefinição entre as tonalidades de Do menor e Mi bemol maior, uma observação que seria retomada um século depois por Heinrich Schenker ("Beethoven: V. Sinfonie" [ $1^{a}$ parte], in Tonwille-I, Viena, Universal Edition, 1921; cf. edição em língua inglesa a cargo de William Drabkin, Oxford, Oxford University Press, 2002). Schenker, porém, afirma ser este um falso juízo, decorrente de se tomar por "motivo principal" apenas os dois compassos iniciais, e não quatro: a repetição da célula básica, ali contida, define a tonalidade menor. É nesta passagem que se separam mais profundamente as duas redações, a da $A M Z$ e a da Kreisleriana: a resenha propriamente dita parte para a descrição e análise detalhada de cada movimento da sinfonia. 
O amável tema em Lá bemol maior do Andante con moto não soa como uma amena voz espectral a nos encher o peito de esperança e confiança? Mas aqui também se introduz o espírito assustador que, no Allegro, arrebatara e intimidara o nosso ânimo [Gemüt], a cada instante insinuando-se para fora das densas nuvens em meio às quais desaparecera, e diante de seus relâmpagos as amigáveis figuras que nos cercavam rapidamente se põem em fuga.

Que dizer do Menuetto? Escutem as singulares modulações, as finalizações no acorde maior dominante, que o baixo retoma como tônica do tema seguinte, em tonalidade menor... e mesmo o tema, que sempre se estende só por mais alguns compassos. Vocês não são novamente capturados por aquele anseio irrequieto e inominável, pelo pressentimento do maravilhoso reino espiritual onde o mestre impera?

Entretanto, irradia-se em fulgurante luminosidade solar o soberbo tema do movimento final, no júbilo exultante da orquestra inteira - os maravilhosos nós contrapontísticos que aqui mais uma vez se atam ao conjunto. Alguns podem até se apressar em julgar tudo isso uma rapsódia genial, mas o âmago [Gemüt] de todo ouvinte atento será arrebatado íntima e profundamente por um sentimento, precisamente aquele anseio indizível e carregado de presságios, e ele não será capaz, até o acorde final, ou melhor, até alguns momentos depois, de deixar o maravilhoso reino espiritual onde dor e prazer, transfigurados em tons, o envolveram.

Quanto à estrutura interna dos movimentos, seu desenvolvimento e orquestração, a maneira como estão encadeados, tudo isso trabalha tendo em vista uma meta; mas é sobretudo a íntima afinidade entre os temas o que confere tal unidade, e somente essa possibilita manter o ouvinte fixo em uma disposição. Com frequência essa afinidade fica clara para o ouvinte, como quando consegue percebê-la pela conexão entre duas partes, ${ }^{11}$ ou descobre nelas uma linha de baixo compartilhada. Há, porém, afinidade mais profunda, que não se manifesta dessa maneira e que via de regra só se comunica de um espírito a outro espírito É exatamente a que rege os movimentos dos dois Allegros e do Menueto, revelando magistralmente a lúcida genialidade do mestre.

Quão profundamente marcaram-me o âmago as tuas majestosas composições para piano, ó elevado mestre! Como me parece raso e insignificante tudo aquilo que não provém de ti, do perspicaz Mozart e do poderoso gênio Sebastian Bach. Qual não foi o meu prazer ao receber tua septuagésima obra, os dois magníficos trios, pois bem sabia que após pouco estudo já poderia escutá-los soberbamente. E saiu-me tão bem esta noite, que mesmo agora não estou disposto a abandonar as sinuosidades e os entrelaçamentos de teus trios, como alguém que vagueia pelos descaminhos de um parque fantástico com toda sorte de árvores raras, arbustos e flores exuberantes, e se embrenha cada vez mais fundo. As graciosas vozes de sereias de suas frases, eloquentes em sua colorida multiplicidade, me enredam mais e mais adentro. O espírito cultivado da dama que hoje executou

${ }^{11}$ O termo original, Sätze, é ambíguo, podendo significar tanto "frases", "motivos" como "movimentos" (as partes em que uma obra se divide). 
soberbamente o Trio $\mathrm{n}^{\mathrm{o}}$ I para mim, o Kapellmeister Kreisler - uma verdadeira honra -, e diante de cujo piano ainda me encontro, escrevendo, me fez ver muito distintamente como devemos atentar somente para o que é dado pelo espírito, todo o resto é penoso. ${ }^{12}$

Acabo de repetir ao piano, de cor, algumas surpreendentes modulações dos dois trios. É verdade que o piano (Flügel-Pianoforte ${ }^{13}$ ) permanece mais apto para a harmonia do que para a melodia. A expressão mais refinada de que o instrumento é capaz não confere à melodia a vida animada em milhares e milhares de nuanças que o arco do violinista ou o fôlego do instrumentista de sopro conseguem criar. O intérprete peleja em vão contra a dificuldade que lhe é imposta pelo mecanismo que, por meio de uma percussão, faz vibrar e soar as cordas. Em compensação, não há nenhum outro instrumento (exceção feita à todavia muito mais limitada harpa) capaz de abarcar o reino da harmonia em acordes plenos como o piano, e de revelar, para o conhecedor, seus tesouros em formas e figuras maravilhosas. Se a fantasia do mestre soube captar toda uma paleta sonora com ricos grupos, luzes claras e sombreamentos profundos, ele então pode, ao piano, trazê-la à vida, de modo que ela aflore colorida e luminosa a partir do mundo interior. A grade musical, esse verdadeiro livro mágico da música, que em seus signos abriga toda a maravilha da arte sonora, o misterioso coro dos mais diversos instrumentos, é vivificada ao piano pelas mãos do mestre, e uma peça como tal, bem executada a plenas vozes a partir da grade, poderia ser equiparada à criteriosa ponta-seca que se copiou de um grande quadro. O piano, portanto, é apropriado sobretudo para o fantasiar, para a redução a partir da grade, para sonatas desacompanhadas, para acordes e assim por diante. Além disso, também para trios, quartetos, quintetos etc., nos quais se introduzem os instrumentos convencionais de cordas, e por este motivo já pertencem completamente ao domínio da composição pianística, pois se são compostos como se deve, ou seja, a quatro, cinco ou mais vozes, tudo repousa no desenvolvimento harmônico, o que por si só impossibilita passagens brilhantes dos instrumentos individuais.

Tenho verdadeira aversão a todos os concertos para piano propriamente ditos. (Os de Mozart e Beethoven não são efetivamente concertos, mas antes sinfonias com piano obbligato.) Aqui deve fazer-se valer a virtuosidade individual do intérprete nas passagens e na expressividade da melodia; contudo, o melhor intérprete tocando o melhor instrumento bate-se em vão para alcançar aquilo que um violinista, por exemplo, consegue com pouco esforço. Após o pleno tutti das cordas e

12 Este parágrafo, o único em que o narrador assume um nome para si, constitui, juntamente com a primeira frase do seguinte, o acréscimo da Kreisleriana que faz a ponte para o restante do texto, extraído da resenha aos trios op. 70, publicada no AMZ no ano de 1813.

${ }^{13}$ Hoffmann utiliza, aqui e nas passagens precedentes da Kreisleriana, o termo Flügel, "asa", que alude ao formato do instrumento em questão, ou melhor, de sua grande caixa de ressonância. Na recensão do op. 70 no $A M Z$ (1813), o termo é Fortepiano, que designa seja o piano, seja um instrumento similar mais antigo, com recursos diferentes. O leitor deve ter em mente que a história das modificações e aprimoramentos do piano está em pleno desenvolvimento e todavia não se consolidou quando da redação desses textos (ver Apresentação). 
sopros, todo solo soa rígido e opaco; admira-se a técnica da digitação e coisas do gênero, sem que se fale propriamente ao coração [Gemüt].

Mas como o mestre soube apreender o espírito mais peculiar do instrumento, e como soube dar-lhe o tratamento mais apropriado!

Um tema Cantabile, simples mas eficaz, e apropriado aos mais diversos tratamentos contrapontísticos, abreviações etc., fundamenta cada movimento; todos os demais temas e figuras auxiliares são internamente ligados ao motivo principal, de maneira que tudo se conecta e se ordena, por meio de todos os instrumentos, até o mais alto grau de unidade. Tal é a estrutura do todo; mas nessa construção artística intercalam-se, revoando irrequietas, as mais maravilhosas imagens, nas quais surgem, perfilados e intricados, prazer e dor, nostalgia e desejo. Figuras incomuns iniciam uma dança aérea, na qual ora flutuam até um ponto luminoso, ora se separam radiantes e fulminantes e então se acossam e se perseguem em diversos grupos; no meio desse desvelado reino de espíritos, a alma entusiasmada escuta o idioma desconhecido e compreende os mais misteriosos pressentimentos que dela se apossaram.

Só penetra realmente nos mistérios da harmonia aquele compositor que consegue, por meio dela, surtir efeito no âmago do homem; para ele, as proporções numéricas - que para o gramático desprovido de gênio permanecem problemas aritméticos rígidos e sem vida - são preparados mágicos com os quais sabe evocar um mundo enfeitiçado.

Apesar da serenidade que particularmente prevalece no primeiro trio, até mesmo no melancólico Largo, o gênio beethoveniano permanece grave e solene. É como se o mestre quisesse dizer que só podemos falar de coisas profundas e misteriosas empregando palavras sublimes e majestosas, e nunca comuns, mesmo quando o espírito internamente se confia àquelas e se sente elevar pacífica e alegremente; a dança dos sacerdotes de Ísis só pode ser acompanhada por um hino de grande júbilo.

Ali onde é necessário efetivar-se apenas enquanto música, e não, por exemplo, servir a um fim dramático determinado, a música instrumental deve livrar-se de todo divertimento insignificante, de todos os entreatos frívolos. O âmago profundo procura pelos indícios [Ahnungen] daquela felicidade que, mais majestosa e bela do que aqui neste mundo estreito, provém de um país desconhecido e acende no peito uma prazerosa vida interior; busca uma expressão mais elevada do que triviais palavras o permitiriam, as quais só convêm à atmosfera terrena que nos circunda. Por si só, essa gravidade de toda a música instrumental e pianística de Beethoven proíbe as arriscadas passagens para cima e para baixo de ambas as mãos, todos os saltos incomuns, os Capricci jocosos, as notas construídas nas alturas com cinco ou seis linhas suplementares, de que estão repletas as composições para piano de tipo mais recente.

No que diz respeito à mera técnica da digitação, as composições para piano do mestre não oferecem nenhuma dificuldade extraordinária, já que as raras escalas, tercinas e congêneres, todo intérprete instruído deve tê-los à mão; mesmo assim, a execução daquelas é excepcionalmente difícil. Alguns assim chamados virtuoses descartam as composições para piano do mestre, acrescentando, à pecha de "difi- 
cílimo", a de "e muito ingrato"! Em termos de dificuldade, é de observar que uma execução correta e conveniente de composições de Beethoven demanda nada menos que o intérprete a compreenda, que penetre profundamente em sua essência, que tenha, em plena consciência, a ousadia de consagrar-se corajosamente a um ritual para adentrar o círculo das aparições mágicas, evocadas por seu poderoso feiticeiro. Quem não sente em si essa vocação, quem vê na sagrada música apenas um gracejo, um modo de ocupar as horas vagas, de estimular por um instante ouvidos embotados, ou algo conveniente à sua própria ostentação, que se abstenha dela. Só alguém assim poderia proferir a reprovação "... e extremamente ingrata!". O verdadeiro artista vive apenas na obra que soube apreender - e agora executa - segundo o intuito do mestre. Ele se recusa a fazer valer, como quer que seja, sua própria personalidade, e todo o seu esforço criativo concentra-se apenas em dar vida, de maneira radiante e multicolor, a todas as imagens e aparições afáveis e majestosas que o mestre, com poderes mágicos, encerrou em sua obra, no intuito de envolver o Homem em círculos luminosos e cintilantes e, inflamando sua fantasia e seu âmago mais íntimo, levá-lo veloz pelos ares até o distante reino espectral dos tons.

Tradução e notas de Bruno Berlendis de Carvalho. 